
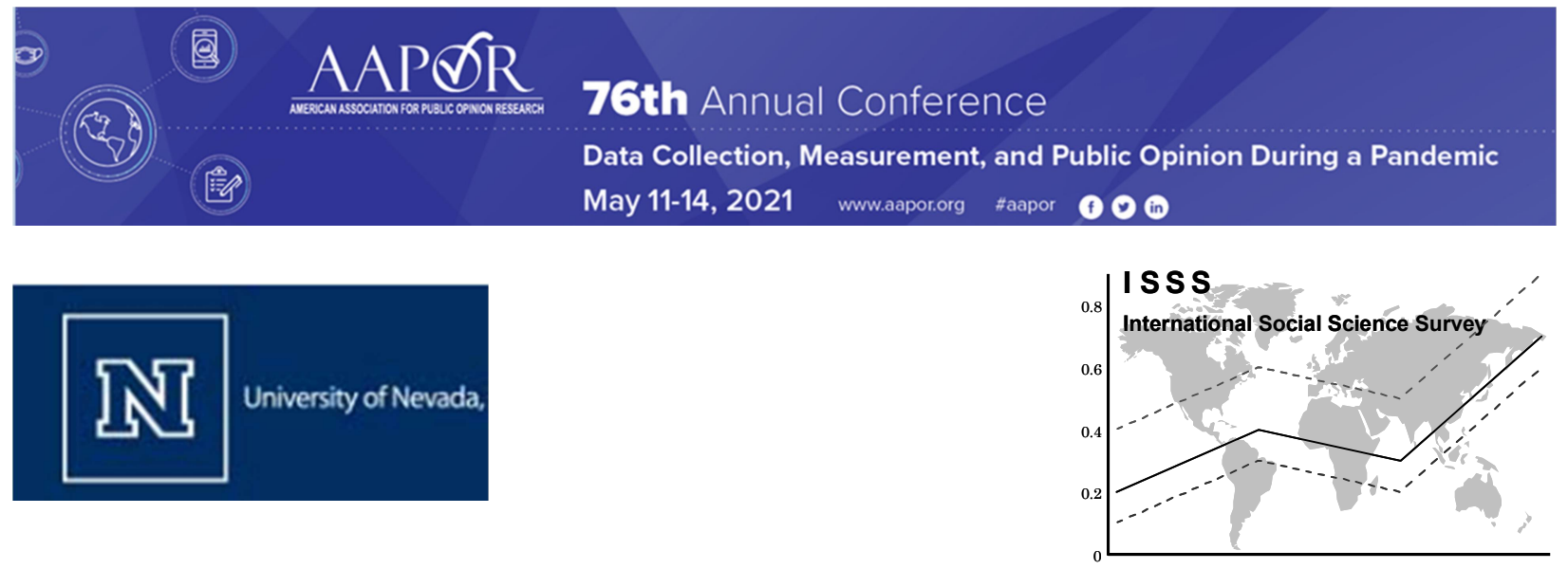

\title{
A Scale for Measuring Social Distancing Behavior: Survey Questions and National Norms, USA 2020
}

MDR Evans,

Department of Sociology and Nevada Agricultural Experiment Station,

University of Nevada, Reno

mariahev2@gmail.com

Jonathan Kelley,

International Social Science Survey \& University of Nevada, Reno

international. survey@gmail.com

Sarah Kelley,

Department of Data Science and Innovation, Child Trends

sarahkelley1759@gmail.com

Paper to be presented to the

Annual Conference of the American Association for Public Opinion Research,

Tuesday, 11 May, 2021 at 3:00pm EDT. 


\section{Abstract}

"Social distancing", a set of "nonpharmaceutical interventions" or NPIs in the medical literature, is a primary defence, perhaps the primary defence, against infectious disease, universally advocated by medical authorities in the US and throughout the world during the current coronavirus pandemic. The idea is not new. Perhaps the first government-directed quarantine system was mid-fourteenthcentury Venice's "quaranta giorni", forty days of mandated isolation for incoming ships. We propose a 5-item primary scale of "social distancing" behavior (KEK-3) and a slightly extended variant (KEK-3m), developed for use during the COVID-19 epidemic (and, potentially, beyond). The candidate items all had 7 answer categories. Assessment aligns very well with the classical measurement model for multi-item scales: interitem correlations are high; alpha reliability is 0.86 ; correlations with criterion variables are similar across the candidate items; factor analysis (oblimin rotation) finds a single dimension with an eigenvalue over 1 and loadings around .7. We provide behavioral norms for America during the 2020 pandemic and describe KEK-3's links to demographic and socioeconomic factors. Developing a replicable scale is especially important now, because many researchers are making erroneous comparisons using the same terminology to describe aspects of the epidemic which have been measured differently. To successfully assess the "...meaning of social change related to COVID-19, the newly emerging social practices due to lockdown measures..." (Esposito, Stark and Squazzoni 2020), high-quality measurements sufficiently reliable and robust to be replicated in different times as the epidemic evolves and in different settings are desperately needed: KEK-3 contributes to such a set of measures. Data: four large national sample surveys conducted April - July, 2020 during the coronavirus

pandemic. Data collection was through Amazon.com's Mechanical Turk. This scale may be freely used by other researchers so long as its origin is acknowledged.

\section{Introduction}

"Social distancing", a set of "nonpharmaceutical interventions" or NPIs in the medical literature (Greenstone and Nigam 2020), is a primary defence, perhaps the primary defence, against infectious disease, universally advocated by medical authorities in the US and throughout the world during the current coronavirus pandemic. The idea is not new. Perhaps the first government-directed quarantine system originated in mid-fourteenthcentury Venice, the "quaranta giorni" or forty days of mandated isolation for incoming ships (Chatterjee and Chauhan 2020).

In this paper we present a reliable, fully tested, multiple-item scale for measuring social distancing behavior, together with behavioral norms for the USA during the 2020 
pandemic, and a description of its links to demographic and socioeconomic factors. Developing a scale that others can replicate is especially important in this epidemic, because many researchers are making erroneous comparisons using the same terminology to describe aspects of the epidemic which have been measured differently (Matthewman and Huppatz 2020). In order to successfully assess the "...meaning of social change related to COVID-19, the newly emerging social practices due to lockdown measures..." (Esposito, Stark and Squazzoni 2020) high-quality measurements sufficiently reliable and robust to be replicated in different times as the epidemic evolves and in different settings are desperately needed (Jarynowski et al. 2020). We aim here to contribute to the development of such a set of measures.

Data are from four large national sample surveys conducted between April and July, 2020 during the coronavirus pandemic. Data collection was through Amazon.com's Mechanical Turk facility. A large majority of respondents took it on a computer with a normal sized screen (so the full wording was visible all at once) rather than on a cell phone.

\section{Item wording (Scale KEK-3 Distancing Behavior)}

These questions were asked after several dozen other questions, mostly on the coronavirus epidemic, so respondents were well primed on coronavirus issues (which we had referred to mostly as the "new coronavirus", or the "Wuhan coronavirus", or "COVID-19" in earlier questions). These questions were asked in internet surveys, so respondents saw the question wording and all the answer categories simultaneously. The vast majority of respondents were answering on a full-sized computer screen (laptop or desktop), not a small cell phone screen, so both question wording and answer categories would have been visible.

The questions together with frequencies choosing each answer (letter labels link to table below and were not shown to respondents):

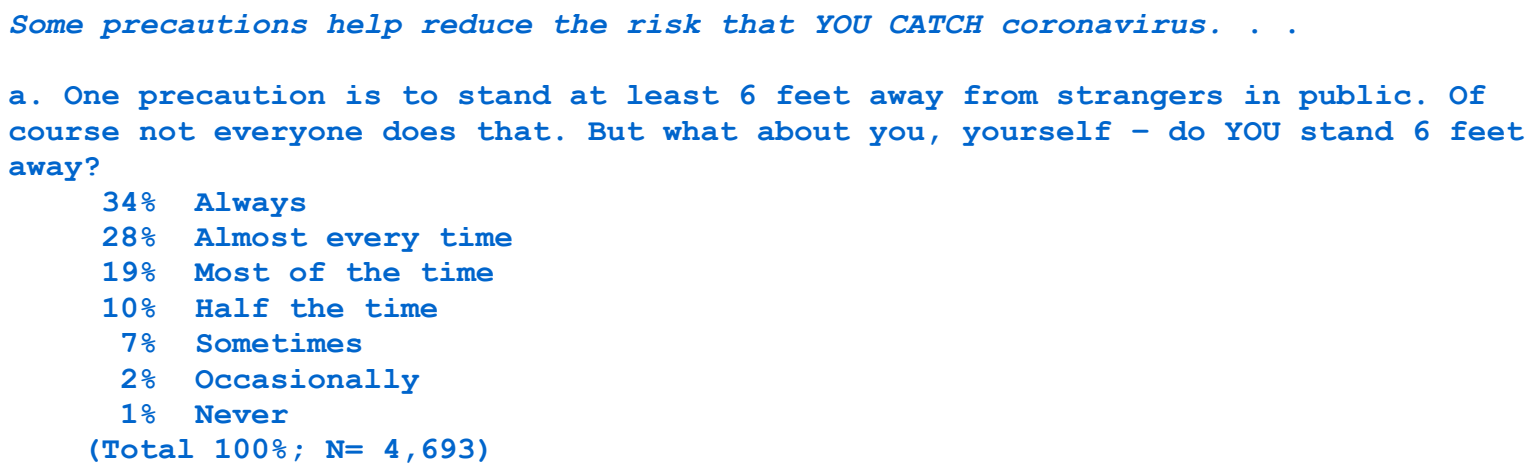


b. Another precaution is not shaking hands when you meet someone (perhaps touching elbows instead, or just saying hello). Do you avoid shaking hands?

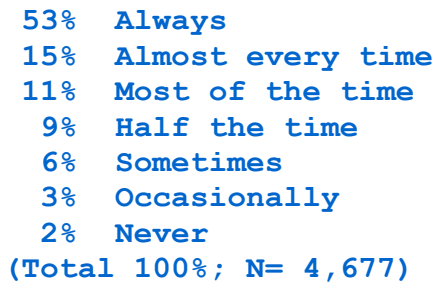

c. How about washing your hands after you have been out in public?

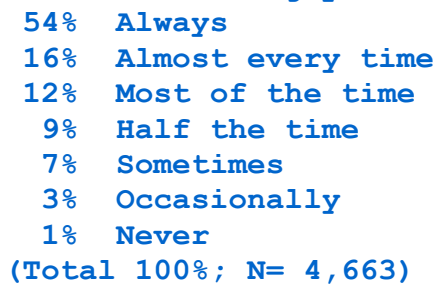

d. How about avoiding parties, stores, and restaurants?

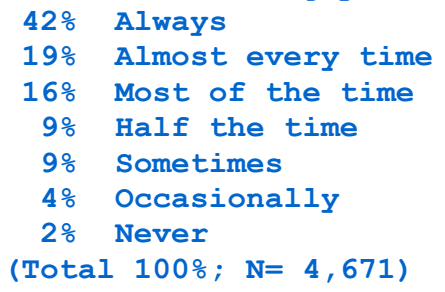

e. Avoiding going to other people's houses or having them come to your house?

42\% Always

19\% Almost every time

$14 \%$ Most of the time

9\% Half the time

9\% Sometimes

5\% Occasionally

3\% Never

(Total 100\%; $\mathrm{N}=4,477$ ) 


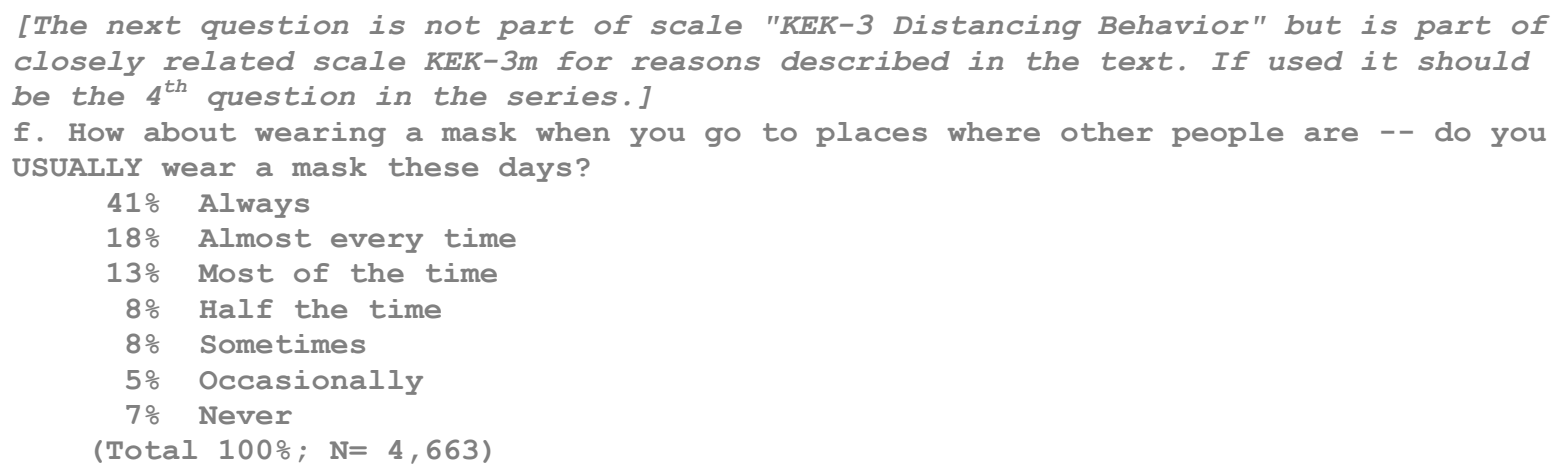

\section{Measurement analysis}

\section{Classical measurement model}

These items have good measurement properties, closely approximating the classical measurement model (Bollen 1989, Treiman 2009) with high correlations among items in the scale, very similar correlations with relevant criterion variables, and appropriately high loading in factor analyses. The Alpha reliability is correspondingly high (.86). 
Table 1. Correlations among social distincing items (Panel 1) and correlations with various criterion variables (Panels 2 to 5). USA April to July 2020 .

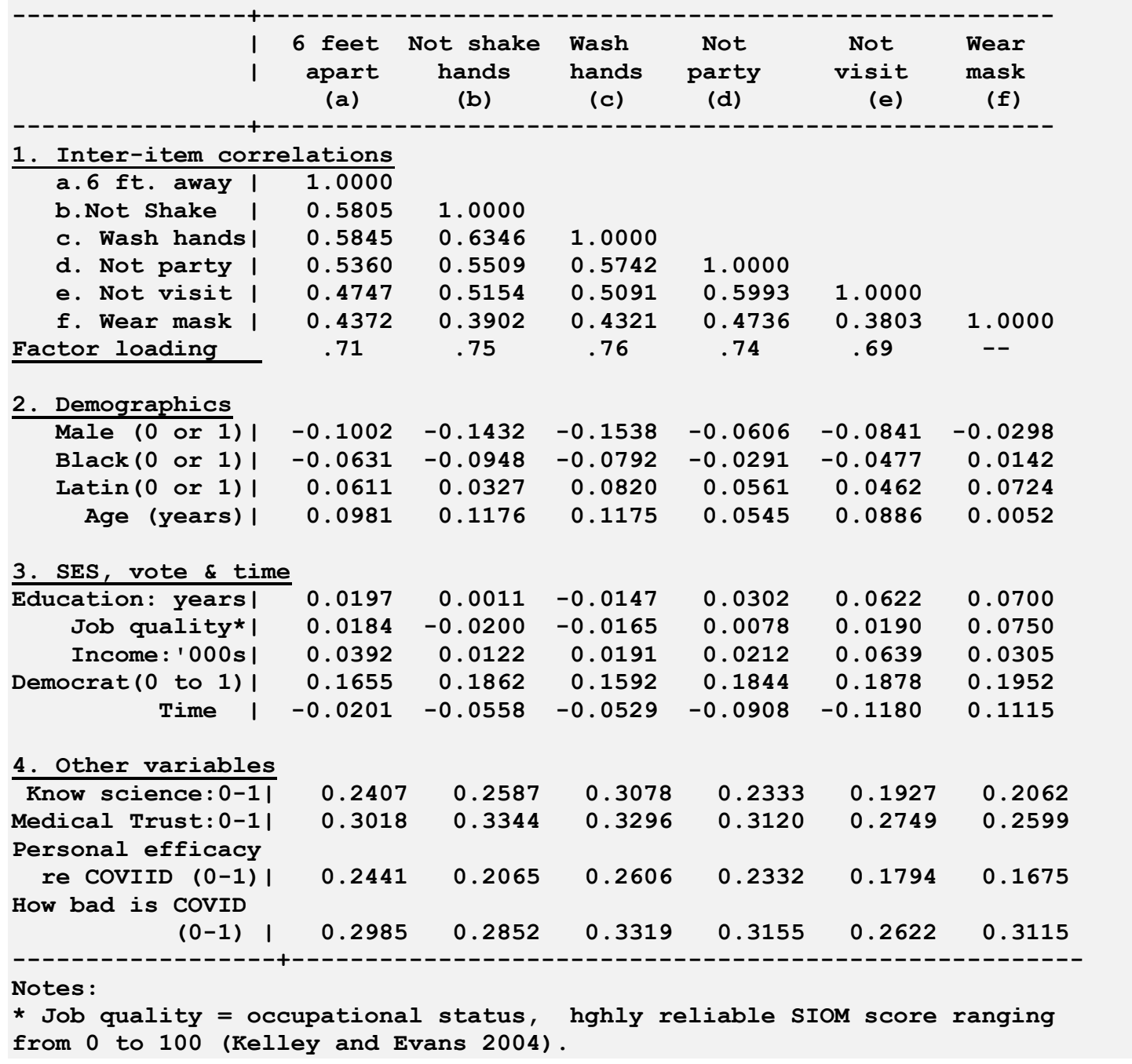

The mean for our US national samples as of April through August 2020, in the midst of the conroavirus pandemic, is 76.5 points out of 100 with a standard deviation of $21(\mathrm{~N}=5,878)$. So the US public claims to be social distancing at about three-quarters of the maximum.

The median is 83 points and the inter-quartile range 60 to 93 . The $10^{\text {th }}$ percentile is 47 points and the $90^{\text {th }}$ is 100 . The distribution at the time this is being written in the midst of the coronavirus pandemic is of course skewed heavily to the right, toward extensive distancing: 


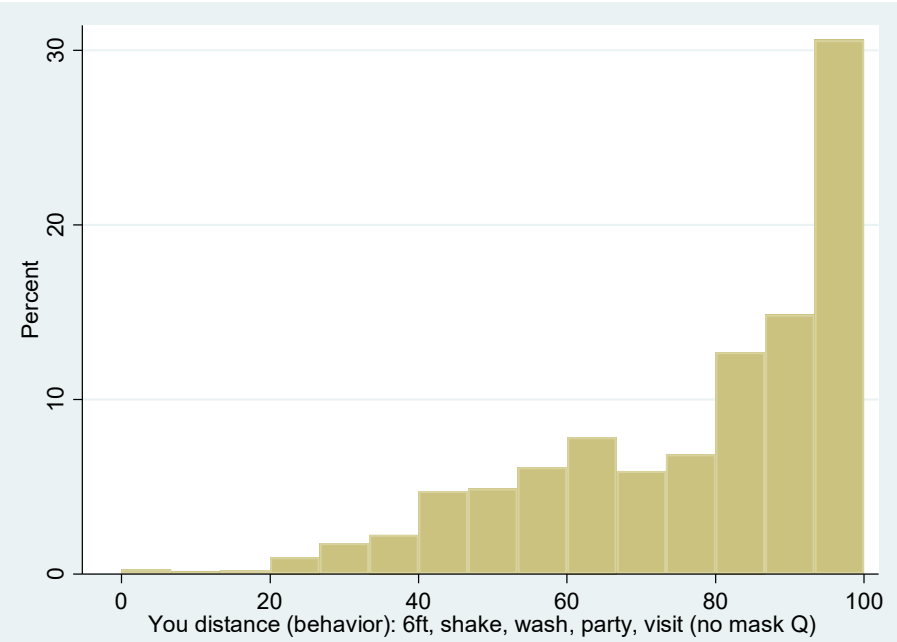

As part of the same battery/module, we also asked about working from home (one question), and self-quarantining (two questions). Self-quarantining formed the focus of early simulations of Covid-19 spread, (Ferguson et al. 2020), although subsequent policy in the US has emphasized "social distancing" practices, such as the items in our scale, which allow people to venture outside their homes, but slow the spread of infection. Analysis showed that the self-quarantining items raised several somewhat distinct issues, and so did not fit the classical measurement model for combined unidimensional scale. They are therefore not included.

\section{Is wearing masks just one more element in social distancing?}

The question on wearing a mask (the last question above) and similar questions on masks asked elsewhere in the survey raise more difficult issues. (1) Conceptually the cloth masks typically worn by the general public (unlike the N-95 masks often worn by medical personnel in clinical settings) offer little or no protection to the wearer; instead they only help protect others from being infected by the wearer. So the element of self-interest in protecting oneself is not present for masks, unlike the other distancing measures which clearly involve self-interest as well as altruism. (2) Masks have a fraught history in this epidemic with many medical authorities advising against them early in the epidemic (sometimes disingenuously, in the hope of preserving scarce supplies for medical personnel) before shifting to urgently recommending for them later on - a mixed and sometimes unpersuasive message. (3) The science about the protective role of the kind of masks available to the general public was not entirely clear, especially early in the epidemic. (4) Aside from their medical efficacy, masks may have taken on a symbolic role signalling one's status as a pro-social being. Thus the role of masks as distancing behavior is rather different than for the other behaviors we are asking about. Accordingly we 
included 2 additional question about masks: Do you wear a mask when shopping and do you wear a mask at work.

Empirically correlations between the masking question and other distancing items are rather lower than the usual pattern (Table 1, Panel 1, row f) which argues against their inclusion in the combined scale on the usual measurement model. The correlations with criterion variables (Table 1, Panels 2, 3, 4, 5 and 5) are fairly similar, which argues for their inclusion. But, the classic measurement model requires both high inter-item correlations and similar correlations with other variables).

Factor analysis is ambiguous on the issue (Table 2). In our exploratory factor analysis, the other items in the scale all have high factor loadings, around a (very satisfactory) .70 to .75 . The three mask items have loadings in the $.50 \mathrm{~s}$, noticeably lower (although a cutoff as low as .50 is accepted in some fields). This suggests the mask questions could be, but may not be, part of the same measurement scale. But evidence against including them in the scale is on the second factor: The loadings (around .35 to .56 ) on a second factor specific to the mask questions are the anomalously high and sharply different from the other items (Table 2, column 2).

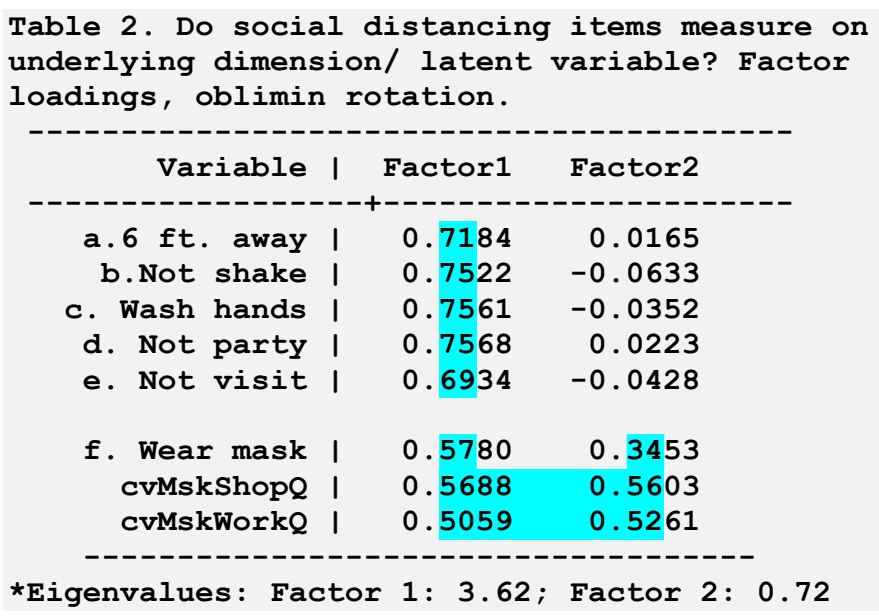

Despite all these empirical, conceptual and historical uncertainties, masks are a significant element in social distancing. They are also (as this is written in August) an element very prominent in public and political discourse. So there is a good argument for including them in a distancing scale, as well as good arguments for excluding them.

For simplicity we exclude them from the main scale (scale KEK-3). Our experience so far with half a dozen analyses done both with the main scale and alternatively with a scale including the one mask question (scale KEK-3m) is that the alternatives lead to virtually identical conclusions. An example is shown below (Table 3, columns 1 and 2). 
Table 3. Regressions using alternative measures of social distancing. USA, 2020.

\begin{tabular}{|c|c|c|c|}
\hline & $\begin{array}{c}\text { KEK-3 } \\
(1)\end{array}$ & $\begin{array}{l}\mathrm{KEK}-3 \mathrm{~m} \\
(2)\end{array}$ & $\begin{array}{l}\text { Mask scale } \\
\text { (3) }\end{array}$ \\
\hline Male (0 or 1$)$ & $-3.31 * \star \star$ & $-2.88 * \star \star$ & $-2.16 * \star$ \\
\hline Black (0 or 1 ) & -1.15 & -0.39 & $2.59 * \star$ \\
\hline Latin ( 0 or 1$)$ & 2.01 & $2.66 *$ & $3.00 *$ \\
\hline Age (years) & $0.15 * \star \star$ & $0.12 * \star \star$ & 0.04 \\
\hline Education (years) & 0.04 & 0.08 & 0.21 \\
\hline Job quality (0 to 100 ) & -1.35 & 0.25 & 1.60 \\
\hline Income (1000s of $\$)$ & $-0.26 * \star \star$ & -0.06 & 0.13 \\
\hline $\operatorname{Democrat}(0$ to 1$)$ & $4.68 * \star \star$ & $5.49 * \star \star$ & $10.70 * \star \star$ \\
\hline Knowledge of science:0-1 & $10.78 * \star \star$ & $10.49 * \star \star$ & $7.26 * \star \star$ \\
\hline Medical trust ( 0 to 1 ) & $20.68 * \star \star$ & $20.98 * \star \star$ & $31.80 * \star \star$ \\
\hline \multicolumn{4}{|l|}{$\frac{\text { Virus origin }}{\text { (Reference categories): }}$} \\
\hline natural origin) & 0 & 0 & 0 \\
\hline Accident, from lab: & $-5.28 * \star \star$ & $-4.91 * \star \star$ & $-3.76 * \star \star$ \\
\hline Chinese government & $-9.16 * \star \star$ & $-8 \cdot 14 * \star \star$ & $-7.06 * \star \star$ \\
\hline US Government & $-13 \cdot 36 * \star \star$ & $-13.06 * \star \star$ & $-13.44 * \star \star$ \\
\hline Other & -3.51 & -2.67 & $-12.10 \star \star \star ~$ \\
\hline $\begin{array}{l}\text { How bad is COVID ( } 0 \text { to } 1 \text { ) } \\
\text { Personal efficacy re }\end{array}$ & $15.90 * \star *$ & $17.43 * * *$ & $16.16 * \star \star$ \\
\hline $\operatorname{covID}^{-}(0$ to 1$)$ & $13.17 * \star \star$ & $12.47 * \star \star$ & $19.62 * \star \star$ \\
\hline Intercept/constant & $35.48 * \star \star$ & $30.39 * \star \star$ & $16.77 * \star \star$ \\
\hline ------------------ & & & --------- \\
\hline $\mathbf{N}$ & 3532 & 3532 & 3532 \\
\hline R-squared & 0.336 & 0.339 & 0.328 \\
\hline
\end{tabular}

Focusing on masks alone (a three-item scale, Alpha reliability $=.86$ ) shows broadly the same picture as the other distancing behaviors (Table 3, column 1 versus column 3 ).

But there are some differences, most notably that mask wearing seems to respond more volatilely to other things - perhaps it is more expressive because it has no self-interest component the way other distancing behaviors do. Democrats are even more distinctively pro-mask than for other distancing behaviors; trust in medical authorities leads even more clearly to mask wearing than to other distancing behaviors; and mask-wearing is even more closely tied to a sense of efficacy.

\section{Conclusion: Scale KEK-3 Distancing Behavior Scale}

We show here that the KEK-3 Distancing Behavior Scale is a reliable, multiple-item scale for measuring social distancing behavior, which has been stringently assessed according to the rules for the classical measurement model. We also present its behavioral norms for the USA during the 2020 pandemic.

This scale is copyright (c) 2020 by the authors but may be freely used by other researchers so long as its origin is acknowledged by reference to this article. 


\section{REFERENCES}

Bollen, Kenneth A. 1989. "Confirmatory Factor Analysis." Pp. 226-318 in Structural Equations with Latent Variables: Wiley-Interscience.

Chatterjeea, Kaushik and V.S. Chauhanb. 2020. "Epidemics, Quarantine and Mental Health." Medical Journal of the Armed Forces India 76(2):125-27. doi: 10.1016/j.mjafi.2020.03.017.

Esposito, lena, David Stark and Flaminio Squazzoni. 2020. "Society after Covid-19." Sociologica 14.(1):1-2, Available at: <https://sociologica.unibo.it/article/view/11015>. doi: 10.6092/issn.1971-8853/11015.

Ferguson, Neil M., Gemma Nedjati-Gilani Daniel Laydon, Natsuko Imai, Kylie Ainslie, Marc Baguelin,, Adhiratha Boonyasiri Sangeeta Bhatia, Zulma Cucunubá, Gina Cuomo-Dannenburg, Amy Dighe, Ilaria, Han Fu Dorigatti, Katy Gaythorpe, Will Green, Arran Hamlet, Wes Hinsley, Lucy C Okell, Sabine van, Hayley Thompson Elsland, Robert Verity, Erik Volz, Haowei Wang, Yuanrong Wang, Patrick GT Walker, and Peter Winskill Caroline Walters, Charles Whittaker, Christl A Donnelly, Steven Riley, Azra C Ghani. 2020. "Impact of Non-Pharmaceutical Interventions(Npis) to Reduce Covid-19 Mortality and Healthcare Demand." Vol. March 16， 2020. London: Imperial College COVID19 Response Team.

Greenstone, Michael and Vishan Nigam. 2020. "Does Social Distancing Matter?". University of Chicago, Becker Friedman Institute for Economics Working Paper No. 202026 https://ssrn.com/abstract=3561244 ( (March 30, 2020). ):https://ssrn.com/abstract=3561244 doi: $\underline{\text { http://dx.doi.org/10.2139/ssrn.3561244 }}$

Jarynowski, Andrzej, Monika Wójta-Kempa, Daniel Płatek and Karolina Czopek. 2020. "Attempt to Understand Public Health Relevant Social Dimensions of Covid-19 Outbreak in Poland (April 5, 2020). Available at Ssrn: Https://Ssrn.Com/Abstract=3570609 or Http://Dx.Doi.Org/10.2139/Ssrn.3570609."

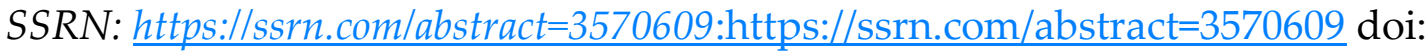
http://dx.doi.org/10.2139/ssrn.3570609.

Kelley, Jonathan and M.D.R. Evans. 2004. "Test-Retest Reliability Estimates for Australian Survey Data: Isssa Results." Australian Social Monitor 7(2):15-16.

Matthewman, Steve and Kate Huppatz. 2020. "A Sociology of Covid-19." Journal of Sociology online before print:10.1177/1440783320939416. doi: $10.1177 / 1440783320939416$. 
Treiman, Donald J. 2009. "Scale Construction." Pp. 241-62 in Quantitative Data Analysis. San Francisco: Jossey-Bass. 